\title{
Innovative and investment development of vegetable growing
}

\author{
Anatoliy Razin ${ }^{1, *}$, Svetlana Taktarova ${ }^{2}$, and Vladimir Semenov ${ }^{3}$ \\ ${ }^{1}$ All-Russian Research Institute of Vegetable Growing - Branch of the Federal Scientific Center for \\ Vegetable Growing, 140153, 500 Building, Vereya, Russia \\ ${ }^{2}$ Penza State University, 440026, Krasnaya str., 40, Penza, Russia \\ ${ }^{3}$ Russian State Agricultural University, 143907, 50 Entuziastov shosse, Balashikha, Russia
}

\begin{abstract}
The purpose of the study is to examine the features of innovative and investment development of vegetable growing. It is substantiated that innovative and investment activities are interrelated, their balanced combination is necessary for further development of the vegetable growing industry. Organizations that produce vegetables have been ranked. A conclusion is made about the need for innovative and investment development of the industry. The organizational and economic mechanism of the innovative and investment development of the industry is proposed, involving the use of public-private partnership, the involvement of industry associations and unions, the introduction of sectoral marketing, bringing the education system in line with the requirements of the innovation economy, the formation of clusters, the deepening of the specialization of organizations within the spatial organization of the country, and the development of infrastructure facilities. Basic innovations for introduction in vegetable growing are considered.
\end{abstract}

\section{Introduction}

In the conditions of prohibition of the food import from the European Union and the United States, the problems of providing the population of the country with vegetables are especially acute. Vegetable growing should develop according to an innovative option, which is characterized by specialization and concentration in large farms, widespread use of achievements in scientific and technical progress, stimulation of attracting investments into the industry, including foreign ones, increasing state support and improving the material and technical base of the industry.

Innovativeness has become an essential feature of the developed economic systems, which causes the need for investment to support economic development.

Innovative and investment activities are interrelated, and their balanced combination in the activities of organizations is needed to determine the necessary amount of investment and the most effective areas of investing in the implementation of innovation.

* Corresponding author: 777razin@ rambler.ru 
According to the Federal State Statistics Service, in 2017, investments in fixed capital of agriculture amounted to 373.4 billion rubles, innovation activity of industry organizations increased by $4 \%$, and the index of agricultural production grew up by $2.4 \%$. This confirms the relevance of the ongoing research, as agriculture becomes the driver of the Russian economy and expands export opportunities.

The purpose of the work is to evaluate innovative and investment development using the example of vegetable growing.

\section{Materials and methods}

In the course of the research, the data of statistical accounting statements of respective organizations were used. The ranking of agricultural vegetable-growing organizations was carried out according to the share of revenue. The dynamics of changes in the crop areas in vegetable growing was studied based on the results of the agricultural census of 2006 and 2016.

\section{Results}

For 2013-2016, the production of vegetables increased by $33 \%$.

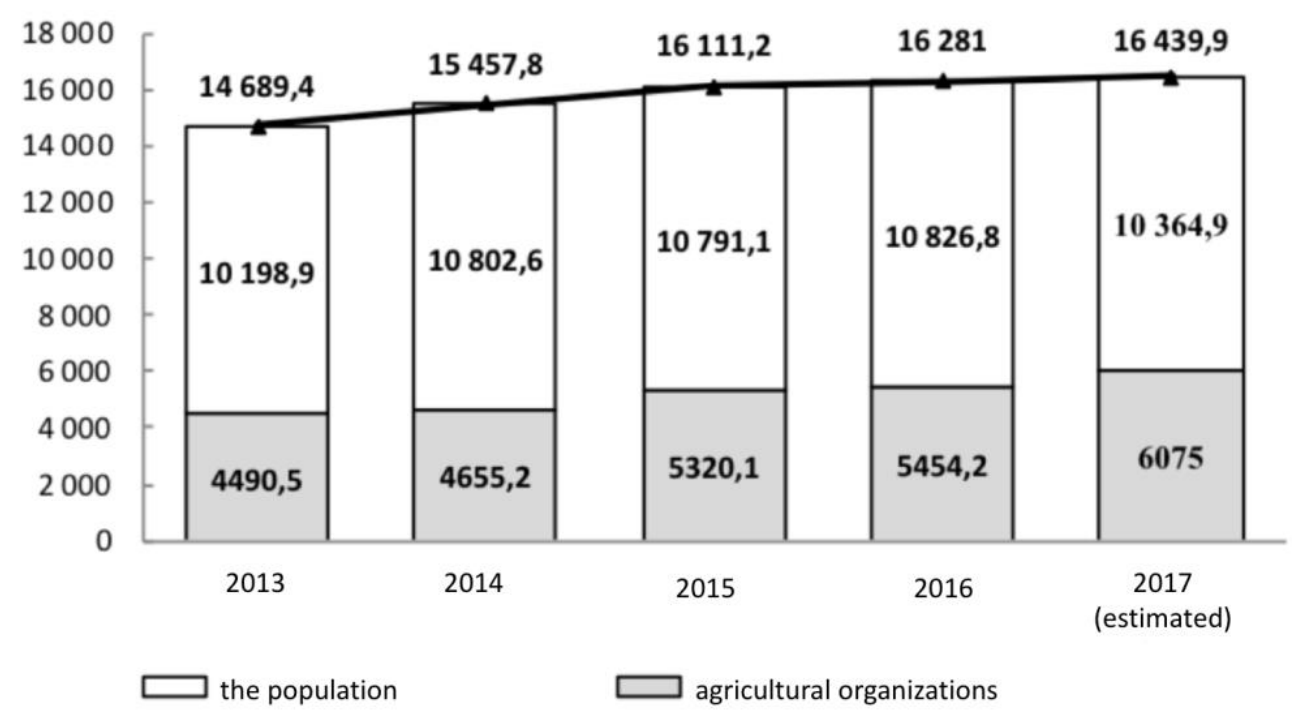

Fig. 1. Dynamics of vegetable production in the Russian Federation [1].

The main production of vegetables is concentrated in the households of the population. They account for $63.1 \%$ of the gross harvest of vegetables in the country. The production of vegetables is developing intensively, as, according to the agricultural census data, the sown areas for all major crops declined (Figure 2). 


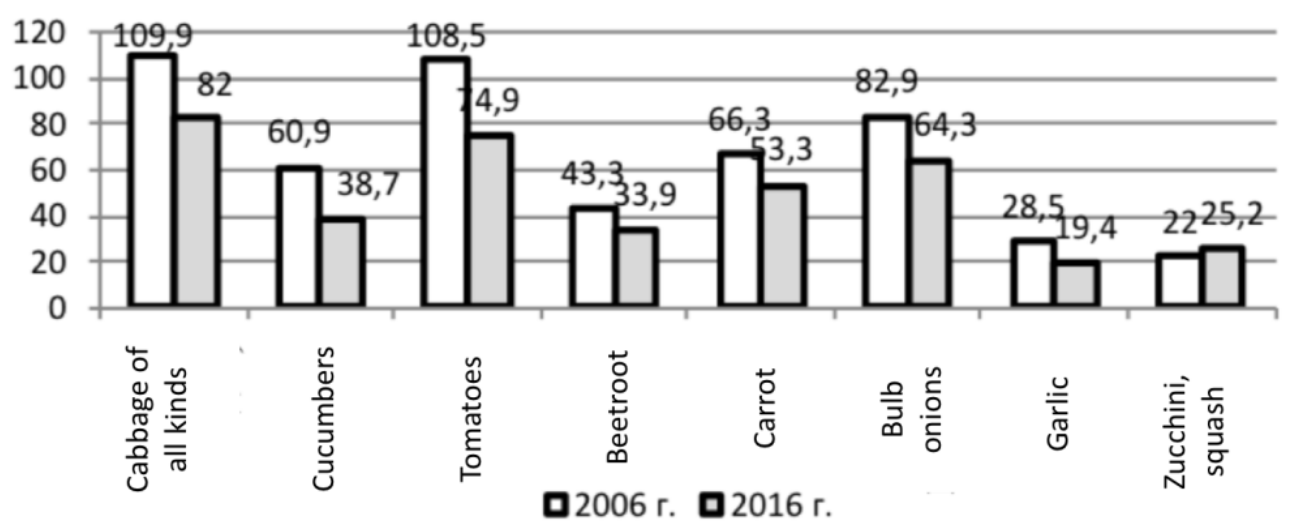

Fig. 2. Sowing area of vegetable crops according to the results of the agricultural census of 2006 and 2016, thousand hectares [2]

Figure 2 presents the leaders of vegetable production (Top-10), ranked by revenue. The leading greenhouse vegetable farms are located next to the largest megacities - St. Petersburg and Moscow, as they have higher demand and higher prices for the sale of products, and it is possible to use industrial heat waste for heating greenhouses. Also it is necessary to note the difference in demand for the types of vegetable products. For example, in Moscow, there is a high demand for broccoli, which is not typical for the regions.

Cucumber and tomatoes predominate in the structure of production of vegetables of protected soil. According to statistical reporting, 625 organizations are engaged in vegetable growing, including 23 of them - in vegetable growing of protected soil.

The revenues of organizations are comparable to assets; the return on assets is $3 \%$ in the medium-sized organizations and $1.75 \%$ in micro-organizations. In 2017, according to Rosstat, gross collection of greenhouse vegetables amounted to 922.2 thousand tons. The country introduced 251 hectares of new greenhouses, so the total area of winter greenhouses amounted to 2270.1 hectares. The new greenhouses of the fifth generation put into operation, are built using the latest technologies and are not inferior to the best foreign analogues. Thanks to this, the yield in new winter greenhouses reaches a record of $60 \mathrm{~kg} /$ $\mathrm{m}^{2}[1]$.

The intensive expansion of foreign seed companies to Russia has led to the fact that about $40 \%$ of all varieties and hybrids of vegetable and melon crops are of foreign origin. These varieties and hybrids are distinguished by good manufacturability, responsiveness to high doses of fertilizers, and the products have beautiful appearance, uniformity in shape and size, but their taste and dietary properties are often inferior to domestic varieties.

In 2017, the Ministry of Agriculture of the Russian Federation adopted a local sector program "Organic Agriculture" within the framework of the priority project "Export of products of agro-industrial complexes". Russia enters the new, international market of organic products, allowing agricultural producers selling their products with the added value. 

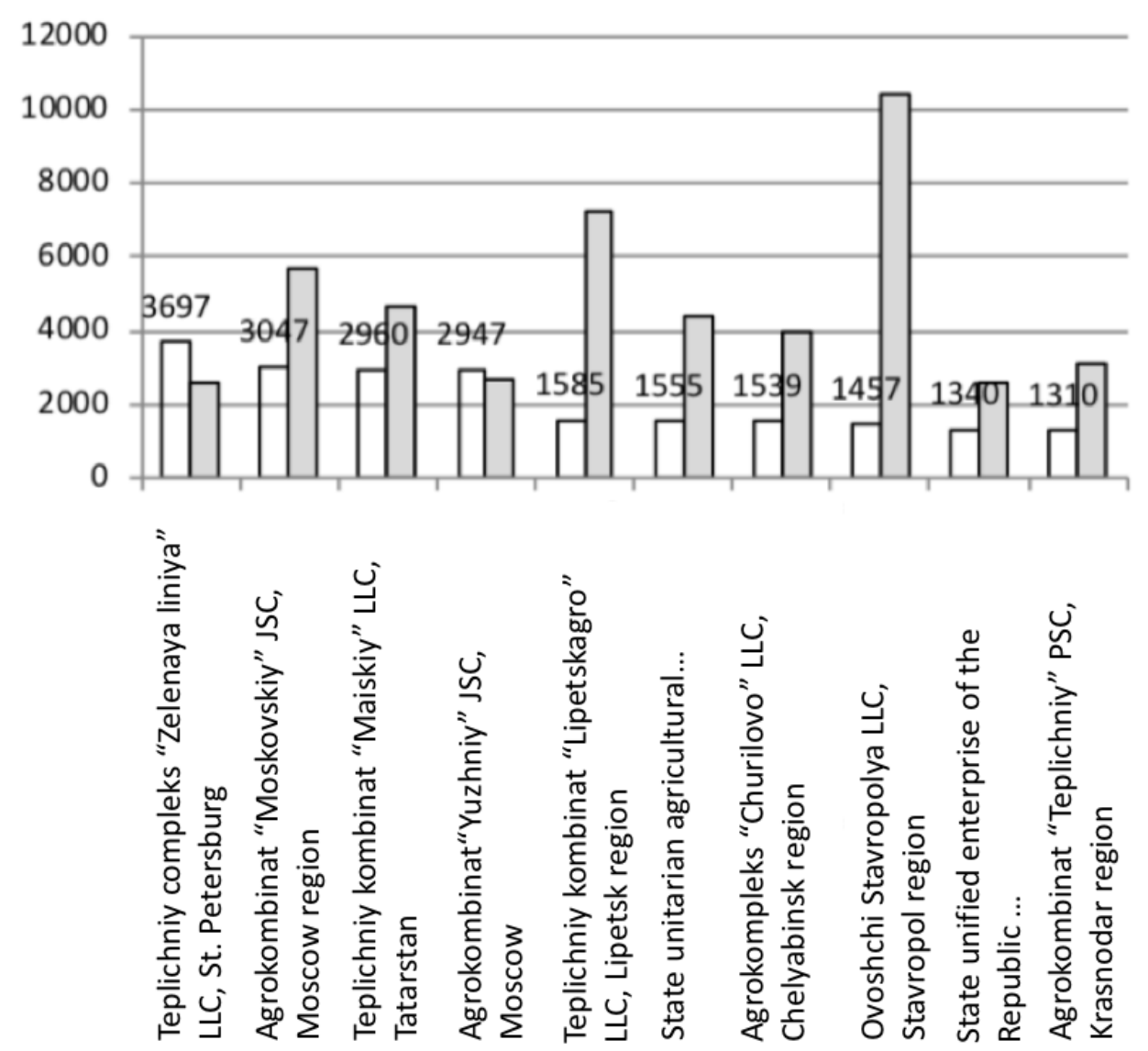

proceeds

assets

Fig. 3. Ranking of organizations for growing vegetables by revenue (compiled by the author).

\section{Discussion}

Further innovation and investment development of the industry should be aimed at its structural reorganization and technological modernization, stimulating the development of existing and creating new scientific and technological, innovative, and scientific and production structures. This is taken into account in the proposed organizational and economic mechanism of innovation and investment development of the industry, presented on the Figure 3.

Further innovation and investment development of the vegetable growing industry involves the use of public-private partnerships, the involvement of industry associations and unions, the introduction of sectoral marketing, bringing the education system in line with the requirements of the innovation economy, the formation of clusters, deepening the specialization of organizations within the spatial organization of the country, and stimulating the development of infrastructure.

To increase the competitiveness of vegetable farms, it is necessary to introduce innovations not only in production, but also to use intangible assets: the search for innovative ideas, marketing research, the development of firm trade, packaging design, 
technological know-how, expanding the range of products and services, enhancing the creative abilities of personnel, introducing new methods of management, and integration with processing organizations.

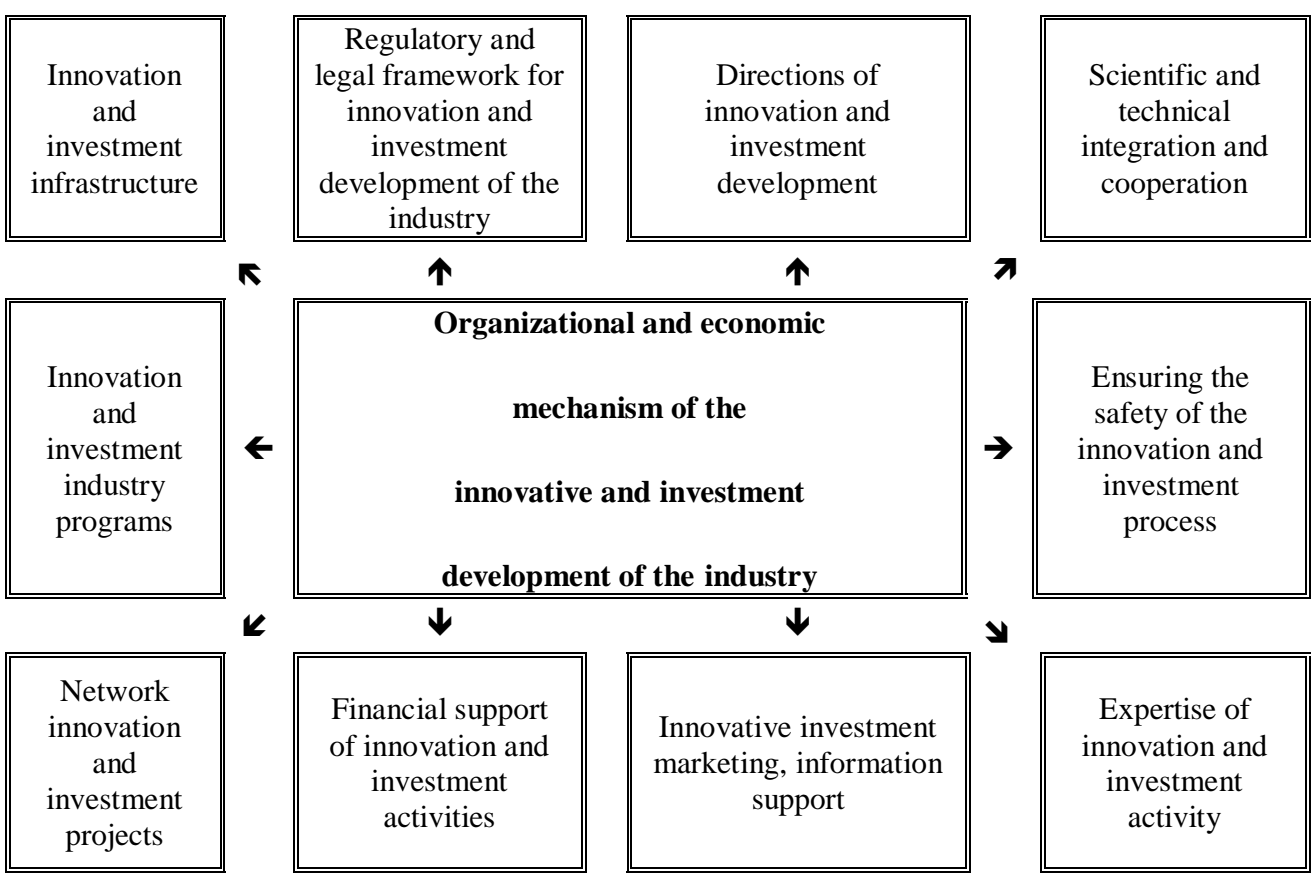

Fig. 3. Organizational and economic mechanism of innovative and investment development of the industry.

Application of the technology of laser pre-sowing seed treatment allows increasing the yield of cucumbers of the first crop rotation on average to $28 \%$, the second crop rotation to $25 \%$, and managing the development of plants, shifting the best fees in the required calendar time. Minimum energy intensity is the advantage of this technology.

Innovations are also applicable in the vegetable growing of protected soil: the use of bumblebees for pollination of vegetable crops allows increasing productivity by $20 \%$. Innovations can also include the use of entomophages to protect against pests and pathogens; growing vegetables with "down-drain" as a result of soil removal and introduction of low-volume technology, which allows growing vegetable crops not in two turns, but in one; growing of vegetable crops in non-traditional terms in conditions of additional illumination (light culture); introduction of energy-saving technologies; the use of a greenhouse film with antioxidants, fog additives, ultraviolet stabilizers, heat-retaining and dispersing additives that increases yield by $10 \%$.

The development of domestic vegetable production on an innovative basis will increase production of vegetables and ensure the country's food security in the sphere of consumption of vegetable products.

\section{Conclusion}

The carried out researches have shown quantitative and qualitative growth in the sector of vegetable growing. Further development is closely related to innovation and investment activities. The proposed organizational and economic mechanism of innovation and investment development will contribute to further progress in the industry. 


\section{References}

1. Rosinformagrotech, National report on the progress and results of the implementation in 2016 of the State Program for the Development of Agriculture and Regulation of Agricultural, Raw Materials and Food Markets for 2013-2020 (Rosinformagrotech, Moscow, 2017)

2. Federal Service of State Statistics, Preliminary results of the All-Russian Agricultural Census of 2016 (Statistics of Russia, Moscow, 2017) 